\title{
LA PREVENCIÓN DE LA SALUD Y SEGURIDAD EN LAS LEYES LABORALES DEL SIGLO XIX
}

\author{
Dra. Isabel Ramos Vázquez \\ Prof $f^{\mathrm{a}}$ Titular de Historia del Derecho y de las Instituciones \\ Universidad de Jaén
}

\begin{abstract}
Las primeras leyes industriales u obreras, frente al principio de la absoluta libertad de trabajo propio de la economía clásica, se centraron fundamentalmente en la protección de los menores y las mujeres, en consideración a su salud y seguridad. La preocupación por la salud y la prevención de los daños pronto se trasladaron también al ámbito del trabajador adulto, porque la mayoría de las medidas adoptadas eran susceptibles de aplicarse a ellos in costes adicionales. Este artículo pretende analizar esas primeras leyes proteccionistas, desarrolladas a lo largo del siglo XIX con un carácter meramente preventivo, desde las leyes de fábrica británicas, que sirvieron como modelo o "ideal type", y con especial atención a la legislación francesa y española.

First factory o labour laws, versus the perfect freedom to work of economic liberalism, focused the protection of children and women considering their health and safety. The concern for health and safety soon were also transferred to men, because most of the measures were readily capable of being applied to them without additional costs. This study aims to analyze these very first protective laws, developed during 19th century with a merely preventive character, starting from British factory acts as a model or "ideal type", and with special attention to French and Spanish legislation.
\end{abstract}

Title: Health and safety in labor law of the XIX century

Palabras clave: Leyes industriales u obreras, siglo XIX, prevención, salud, seguridad. Keywords: Factory or labour laws, 19th century, prevention, health, safety.

IUSLabor 3/2019, ISSN 1699-2938, p. 228-258

DOI. 10.31009/IUSLabor.2019.i03.11

Fecha envío: 8.10.2019 | Fecha aceptación: 15.10.2019 


\section{Sumario}

1. Introducción

2. La preocupación por la salud y la seguridad de los niños y de las mujeres como detonante de las primeras leyes de fábrica en el Reino Unido

3. Siguiendo la estela británica: la protección de la salud y la seguridad de los niños y de las mujeres en otros lugares de Europa, con particular atención a Francia y España

4. La ampliación de la protección para todos: la prevención de la salud y seguridad del trabajador adulto en las leyes de fábrica del Reino Unido

5. Leyes de higiene y prevención de la seguridad para todos los trabajadores en Francia y en España

6. Conclusiones 


\section{Introducción}

Las primeras leyes de fábrica, industriales, obreras o laborales que, frente al principio de la absoluta libertad de contratación, comenzaron a proteger primero a los colectivos más débiles de trabajadores, los menores y las mujeres, y poco a poco fueron ampliando su protección también al trabajador adulto, se preocuparon fundamentalmente por la salud y la seguridad de los mismos. Podría decirse que estos fueron los primeros ámbitos de la intervención pública a lo largo del siglo XIX, y sobre ellos se focaliza el objeto de estudio.

Tales normas apremiaban a los empresarios a garantizar jornadas reducidas y descansos para los menores y las mujeres, para prevenir los efectos negativos de un trabajo excesivo en su salud; a prohibir el trabajo nocturno o en industrias peligrosas $o$ insalubres a estos especiales colectivos por los mismos motivos; y a adoptar, por lo demás, ciertas medidas de limpieza, ventilación, orden o disciplina para prevenir accidentes de trabajo o enfermedades. Su objetivo, en consecuencia, era de mera prevención, sin ocuparse todavía de la reparación o indemnización de accidentes o enfermedades profesionales, debido a que tanto en el contract of service anglosajón, como en el arrendamiento de obra o servicio (locatio conductio) de base iusromanista que se aplicaba en el Europa continental, era el trabajador quien asumía todos los riesgos derivados del trabajo ${ }^{1}$.

El tránsito desde esta teoría contractual, que liberaba al patrono de cualquier riesgo con la mera satisfacción del salario, y permitía sólo la reclamación de daños a través de la teoría general de la culpa o responsabilidad aquiliana (de muy difícil prueba), hacia nuevas teorías sobre la responsabilidad objetiva del empresario (las teorías del riesgo profesional), que abrieron definitivamente la puerta a la reparación, indemnización o compensación de accidentes y enfermedades del trabajo, se produciría a lo largo del siglo XIX de forma paralela al avance de la cuestión obrera y la legislación social. Pero hasta su pleno reconocimiento a finales de siglo, a partir de la ley alemana de seguros de

\footnotetext{
${ }^{1}$ BAYÓn ChAcón, G., La autonomía de la voluntad en el Derecho del Trabajo. Límites a la libertad contractual en el Derecho histórico español, Tecnos, Madrid, 1955, pp.68-79, Hesse, P.J., "Les accidents du travail et l'idée de responsabilité au XIX ${ }^{\mathrm{e}}$ siècle", Histoire des accidents du travail, n 6-1979, pp.61102, HARRIs, J., Private lives, public spirits. A social history of Britain 1870-1914, Oxford, 1993, pp.120144, MARKHAM, V., "The employers's liability/ workmen's compensation debate of the 1890s revisited", The historical Journal, n44, 2 (2001), pp.471-495, CotTerEaU, Alain, "Droit et bon droit. Un droit des ouvriers instauré, puis évincé par le droit du travail (France, XIXe siècle)", Annales HSS, n 2, nov.-déc. 2006, pp. 1521- 1557, o RAmos VÁzQueZ, I., "Marco jurídico de las relaciones de trabajo en el siglo XIX. Del antecedente de locatio conductio, la influencia del louage d'ouvrage et d'industrie, hasta el arrendamiento de obras y servicios", Anuario de Historia del Derecho Español, tomo LXXXVI (2016), pp.547-574.
} 
accidentes de trabajo de 1884 (la Workmen's Compensation Act británica de 1897, las leyes francesa y danesa del año 1898, o la ley de accidentes de trabajo española de 1900), hubo una fase previa en la que sólo se contemplaron medidas de carácter preventivo.

La finalidad de este artículo es analizar exclusivamente dicha fase previa de prevención de la salud y la seguridad en el trabajo, sin entrar en las concretas medidas de reparación o indemnización, a partir del estudio de las primeras leyes de fábrica británicas o "factory acts", que debido a la temprana industrialización del Reino Unido se convirtieron en el modelo o "ideal type" a seguir por los países europeos que se industrializaron de forma más tardía. De forma especial se atenderá también al desarrollo de la legislación industrial francesa, por cercanía geográfica y capacidad de influencia, y por supuesto a la primigenia legislación social u obrera española.

\section{La preocupación por la salud y la seguridad de los niños y de las mujeres como detonante de las primeras leyes de fábrica en el Reino Unido}

Entre finales del siglo XVIII y comienzos del XIX, el pensamiento humanista ilustrado, el paternalismo o proteccionismo del Estado, y nuevas corrientes pedagógicas desarrolladas incluso desde la literatura, propiciaron un cambio de trascendental importancia en la consideración de la infancia ${ }^{2}$. Si antes olvidados por el derecho y considerados meramente una propiedad del padre o la familia, que ejercían su autoridad sobre ellos sin ningún tipo de limitaciones, o bien un pesado lastre para el Estado cuando eran huérfanos o abandonados; los niños adquirieran en este tiempo un novedoso valor social como depositarios del futuro de la comunidad, empezaron a ser vistos como un importante recurso o riqueza del Estado, y se convirtieron en objeto de atención pública.

Esta nueva imagen positiva y revalorizada de la infancia tuvo su inmediato reflejo en el ámbito del trabajo, dando lugar, como es sabido, a la aparición de las primeras leyes obreras, industriales o de fábrica, cuyo objetivo inicial era exclusivamente la protección de los niños en el trabajo. A ellas coadyuvaron en particular las nuevas doctrinas económicas y jurídicas que, frente a la economía clásica o el liberalismo radical, denunciaban los efectos más negativos del sistema privado de la autonomía de la

\footnotetext{
2 JoRDANOVA, L., "New worlds for children in the Eighteenth century: Problems of historical interpretation", History of the Human Sciences, n' 3/1 (1990), pp. 69-83, o O 'MALLEY, A., The making of the modern child: Children's literature and childhood in the late Eighteenth century, New York, 2003.
} 
voluntad en la contratación de los niños, y la necesidad de una intervención pública desde la "caridad legal" o la defensa de un "minimun nacional" para protegerlos ${ }^{3}$.

De ellas surgió una nueva interpretación jurídica de la teoría contractualista clásica, que se oponía a la absoluta autoridad paterna en la contratación del trabajo de sus hijos, bajo el argumento de que los niños no tenían ninguna capacidad o libertad contractual ("freedom of contract in the case of children is but another word for freedom of coercion", en palabras de John Stuart Mill ${ }^{4}$ ), e impulsó definitivamente la aparición de las primeras leyes protectoras de los niños trabajadores en la pionera Gran Bretaña ${ }^{5}$.

Frente a las leyes del Antiguo Régimen, que sólo se preocupaban de apartarlos de la mendicidad o vagancia, tratando de que aprendieran un oficio y fueran productivos para el Estado (a través de las llamadas "poor laws" o "apprentices acts" en el Reino Unido, "loi sur mendiants et vagabonds" en Francia, o "de mendigos o vagos" en España), el principal mérito de estas nuevas leyes fue que por primera vez comenzaron a preocuparse por la salud y el desarrollo personal de los niños, regulando sus jornadas y horarios de trabajo para que pudieran acudir a la escuela, e impulsando también las primeras medidas de higiene y seguridad para ellos en las industrias.

Aunque hubo otras tempranas voces de filántropos ilustrados que denunciaron la situación de los niños ante el trabajo a finales del Antiguo Régimen, ya fueran pobres tutelados por el Estado o chicos de baja o mediana clase social obligados a trabajar para ayudar a sus familias, la más influyente de ellas fue sin duda la de Jonas Hanway ${ }^{6}$. Sus denuncias consiguieron que se debatiera por vez primera en el Parlamento inglés la frustrada Jonas Hanway Act de 1767, que pretendía prohibir el trabajo en las fábricas de algodón a menores de 6 años.

A los tratados específicos sobre las negativas consecuencias que las larguísimas jornadas de trabajo provocaban en la salud de los niños en la industria del algodón de HANWAY (1767) o RADCLIFFE (1784), se sumaron nuevos estudios en el tránsito de siglo, promovidos por médicos como el Dr, Percival o el Dr. Ferriar, filántropos como Sir Leslie Stephen, William Eden o William Sabatier, o incluso sociedades humanitarias

\footnotetext{
${ }^{3}$ Dunlop, O.J., and Denman, R.D., English apprentices and child labour: a history, London, 1912, o Keeling, F., Child labour in the United Kingdom: a study in the development and administration of the law relating to the employment of children, London, 1914.

${ }^{4}$ Cfr. Ramm, T., "Laissez-faire and State Protection of Workers", The making of labour law in Europe, London and New York, 2010, p.79.

${ }^{5}$ Hutt, W. H., "The Factory System of the Early Nineteenth Century", Capitalism and the Historians, University of Chicago Press, 1954, o Fraser, D., The Evolution of the British Welfare State, 2d ed. London, 1984.

${ }^{6}$ Hanway, J., The importance of the rising generation, London, 1767.
} 
que se crearon exclusivamente con este fin. Voces tan autorizadas como las de Robert Owen o Robert Peel introdujeron, por su parte, este debate en el Parlamento ${ }^{7}$.

No obstante, desde el punto de vista jurídico, los primeros logros conseguidos por este movimiento se ciñeron meramente a ciertas resoluciones de magistrados locales, por ejemplo, las de los magistrados de Manchester de 1784, que pedían más control de los jueces sobre los aprendices de sus respectivas jurisdicciones, y recomendaban limitar las horas de trabajo de los niños en la industria. Aunque inspiradas claramente por un espíritu de carácter humanitario, estas resoluciones se comprendieron en el marco general de las apprentices acts o leyes de pobres de épocas pasadas, y fueron fácilmente asumidas por los propios industriales y la opinión pública.

Lo mismo ocurrió con la primera ley de carácter general propiamente obrera o de fábrica ("factory act"), promovida por Robert Peel en el Parlamento y dirigida a la protección de los aprendices en los molinos y la industria del algodón, la Health and Morals of Apprentices Act de 1802, que fue aprobada prácticamente sin ninguna oposición, según su promotor porque se entendió como una manifestación más de las antiguas Apprentices acts.

La Health and Morals of Apprentices Act de 1802 regulaba las condiciones de trabajo de los aprendices en los molinos y fábricas de algodón que tuvieran más de veinte personas empleadas. Establecía un máximo de doce horas de trabajo diario para los niños, preocupándose por su educación y formación religiosa, y la prohibición de que trabajaran por la noche. Pero lo que interesa principalmente al objeto de este estudio, es que incorporó las primeras disposiciones sobre higiene en el ámbito del trabajo: en primer lugar, obligaba a los dueños a tener los establecimientos bien ventilados para evitar los efectos negativos de los efluvios y gases nocivos; en segundo lugar, les conmina a encalarlos al menos dos veces al año también por razones de salubridad; y en tercer lugar, aunque esta era más bien una medida relacionada con la moral, les urgía a que tuvieran habitaciones separadas por sexos, y a que tuvieran como mínimo una cama por cada dos aprendices en las habitaciones ${ }^{8}$.

Lamentablemente, la Health and Morals of Apprentices Act de 1802 no fue demasiado efectiva, en parte porque muchos industriales la desconocían, y en parte porque tano el sistema de inspección (una visita anual de dos inspectores nombrados por el juez local), como las sanciones establecidas, no resultaron lo suficientemente disuasorias. Además, frente al sistema de los aprendices, propio de tiempos pasados, la introducción de

\footnotetext{
${ }^{7}$ HUtChins, B.L., AND HARrison, A., A history of factory legislation, $2^{\circ}$ ed., London, 1911, pp.1-13.

${ }^{8}$ The statutes of the United Kingdom of Great Britain and Ireland, vol.I (containing the Acts 41 Geo III 1801 and 42 Geo III 1802), London, 1819, n.42 Geo III c.73.
} 
máquinas y nuevas técnicas, y la aparición de industrias a gran escala en lugares muy poblados, estaban impulsando la práctica de contratar "free children" o "childworkers" en vez de "apprentices", lo que permitía a los empresarios no tener que cumplir la norma y carecer de cualquier tipo de responsabilidad sobre ellos ${ }^{9}$.

Esta situación fue acusada por el propio Robert Owen, que quiso extender la regulación de los aprendices a los niños trabajadores libres, y consiguió que Robert Peel presentara un informe sobre la situación ante el Parlamento en el año 1815. La ley que finalmente se aprobó tres años después, la Cotton Mills and Factories Act de 1819, rebajó mucho las expectativas del proyecto original de Owen, pero al menos consiguió que se estableciera la prohibición de contratar en esas fábricas de menores de 9 años, y mantuvo la restricción de doce horas de trabajo diario para niños de entre 9 y 16, fueran o no aprendices ${ }^{10}$.

A partir de ahí, otra larga serie de leyes fueron ampliando la protección de los niños en el trabajo y fomentando medidas para su educación dentro de las fábricas. La Cotton Mills Regulation Act de 1825 vino a limitar el abuso de hacer trabajar a los menores durante la hora y media de la comida, generalmente en la limpieza de las máquinas, sin respetar la jornada máxima, y también recogió como disposición la costumbre de trabajar menos los sábados, rebajando la jornada para ellos en estos días a nueve horas. Por su parte, la Labour in Cotton Mills Act (Hobhouse's Act) de 1831, reguló el procedimiento ante los jueces de paz por incumplimiento de estas disposiciones, extendió la jornada máxima de doce horas a los menores de 18 años, como originariamente había propuesto Owen, y prohibió el trabajo nocturno a los menores de 21 años con carácter general.

Tras el frustrado intento de Michael Sadler, quien ocupó un escaño en el Parlamento en 1831, de que se aprobara la Ten Hour Bill para limitar aún más la jornada de los jóvenes, ampliando el número de industrias afectadas y potenciando su educación, y el también malogrado proyecto de ley que presentó en 1833 su sucesor Anthony Ashley, la comisión parlamentaria encargada de estudiar la cuestión logró que finalmente se aprobase una nueva Factory Act en 1833, conocida como la Althorp's Act. La norma ampliaba la protección de los niños a todas las industrias textiles y no sólo a la de algodón (con la excepción de la industria de seda), ratificó la jornada máxima de doce horas para los menores de 18 años, así como la hora y media de comida, y fijó finalmente la prohibición del trabajo nocturno para jóvenes menores de 18 años.

\footnotetext{
${ }^{9}$ Maclennan, M., Fitz, J., AND Sullivan, J., Working children, London, 1985, Fyfe, A., Child Labour, Cambridge, 1989, o Nardinelli, C., Child Labor and the Industrial Revolution, Indiana University Press, 1990.

${ }^{10}$ Hutchins, B.L., AND Harrison, A., A history of factory legislation, $2^{\circ}$ ed., London, 1911, pp.14-29.
} 
Otro aspecto relevante de esta norma fue la creación por vez primera de un servicio de inspección específico, a través del nombramiento por el gobierno de un equipo de cuatro inspectores de fábrica, subordinados a una oficina central, que podían entrar libremente en todos los establecimientos para examinar el trabajo de los niños, y estaban obligados a emitir al menos dos informes anuales, elevándose las multas en caso de infracciones.

En el nuevo gobierno formado por Robert Peel en 1841, y en cierta medida incitado por las continuas denuncias de Ashley, su Secretario de Interior James Graham retomó la cuestión de los niños trabajadores ${ }^{11}$. Se conocieron entonces algunos de los informes que ya habían sido capaces de redactar los inspectores de trabajo, que además de señalar las dificultades de conciliar la enseñanza con el horario de los jóvenes trabajadores, pusieron de relieve nuevamente el problema de su salubridad y de su seguridad, e introdujeron la problemática de las mujeres.

En particular, un informe presentado en la primera legislativa de 1842 en relación al trabajo de los niños en las minas, demostraba que también eran muchas las mujeres empleadas en este sector haciendo labores bajo tierra en muy duras condiciones. La cuestión de la mujer trabajadora se sumó así a la de los menores, presentándose nuevos informes sobre su pesarosa situación no sólo en las minas, sino también en la industria textil. Los inspectores apuntaron muy particularmente el elevadísimo número de accidentes laborales que sufrían las mujeres y los niños en este sector, por ser ellos principalmente los que manipulaban, limpiaban y desatascaban las máquinas.

En el caso de las mujeres, los especiales motivos que se adujeron en particulares informes, estudios y análisis para proteger su salud y seguridad eran diferentes a los de los menores, y tenían que ver con la debilidad natural que se presumía de ellas y con la necesidad de garantizar su papel en la sociedad como procreadoras, cuidadoras y madres $^{12}$. Con este objetivo, James Graham presentó un nuevo proyecto de ley ante el Parlamento británico que pretendía superar y derogar a la Factory Act de 1833, y del que finalmente resultaría la aprobación de la Graham's Factory Act de 1844.

La Graham's Factory Act de 1844 amplió por primera vez la protección de los menores en la industria textil a las mujeres (jornada máxima de doce horas, limitada los sábados,

\footnotetext{
${ }^{11}$ Simon, B., Education and the labour movement, London, 1965, Vincent, D., Bread, knowledge and freedom: A study of nineteenth-century working class, London, 1981, o Mizen, P., "Learning the hard way: the extent and significance of child working in Britain", British Journal of education and work, $\mathrm{n}^{\circ} 5$ (1992), pp.5-17.

${ }^{12}$ Rose, S., "Gender and Labor History the Nineteenth Century Legacy", International Review of Social History, ${ }^{\circ} 38$ (1993), pp.145-162, o NASH, M., "Identidad cultural de género, discurso de la domesticidad y la definición del trabajo de las mujeres en la España del siglo XIX", Historia de las mujeres. El siglo XIX, Taurus, Madrid, 1993, Tomo IV, pp. 585-597.
} 
y prohibición del trabajo nocturno), y también introdujo algunas mejoras en el servicio de inspección, que se dotó de mayores instrumentos de control (relojes públicos, certificaciones y apuntes públicos de las horas de trabajo, etc.). Por lo que respecta a las medidas de salubridad, destaca el hecho de que además de las anteriores medidas sobre higiene y limpieza del establecimiento (ventilación, encalado, habitaciones y camas suficientes), introdujo una primera disposición propiamente de seguridad para prevenir los accidentes de trabajo: la interdicción de que tanto los menores como las mujeres pudieran manipular o limpiar máquinas en movimiento.

Tras comprobarse los satisfactorios resultados de la Factory Act de 1844, especialmente a partir de los años sesenta se vivió en el Reino Unido un particular momento de extensión de la protección de los menores y las mujeres desde la industria textil a otros sectores de la industria y del comercio (blanqueo o tintorería, alfarería, fabricación de fósforos o cerillas, papelería, fabricación de cartuchos, vidrio, encajes, sastrería, panadería, lavandería...). Las numerosas normas que comenzaron a dictarse durante estos años a tal objeto, señalaron y regularon las distintas fábricas consideradas peligrosas o insalubres por la utilización de determinadas máquinas o materiales (polvo blanco, colorantes, loza, fósforo...), excluyendo los talleres familiares o industrias domésticas que no usaran energía eléctrica o emplearan a menos de cincuenta personas $^{13}$.

Estas leyes específicas de las industrias peligrosas o insalubres no sólo apartaron o limitaron la contratación de menores o mujeres en ellas, sino que señalaron especiales medidas de higiene y salubridad según el tipo de industria. De entre todas ellas, cabe destacar especialmente la ley de fábrica de 1864, que se refería a varias industrias diferentes (de alfarería, fabricación de casquillos o cartuchos, y papelería), y que incorporó claramente los resultados de los informes realizados por distintos médicos o higienistas ingleses, a los que había consultado la propia comisión redactora, sobre los daños de los gases nocivos, el polvo y otras impurezas generadas en la fabricación.

\section{Siguiendo la estela británica: la protección de la salud y la seguridad de los niños y de las mujeres en otros lugares de Europa, con particular atención a Francia y España}

La tendencia humanitaria y protectora de los niños y las mujeres en el trabajo, no tardó en extenderse desde Gran Bretaña a otros lugares de Europa, que siguieron su ejemplo. Una de las más tempranas leyes protectoras del trabajo de los niños que se promulgó en

\footnotetext{
${ }^{13}$ Hutchins, B.L., AND HARrison, A., A history of factory legislation, $2^{\circ}$ ed., London, 1911, pp.201-222, Thomas, M.W., The early factory legislation: a study in legislative and administrative evolution, Leigh on Sea, 1948, 220-249, o HuNT, E.H., British labour history. 1815-1914, London, 1981, pp.46-47.
} 
la Europa continental siguiendo las pautas británicas, fue una ley promulgada en Prusia en 1839 que también prohibía el trabajo a menores de 9 años, establecía una jornada máxima de diez horas diarias para los menores de 16 años, fomentando su la educación, e introducía algunas medidas de higiene en los establecimientos.

El siguiente país en seguir el ejemplo (casi a la par que Austria) sería Francia, donde, después de dilatar la cuestión durante años, y pedir estudios específicos sobre la misma, como el que la Academia de Ciencias Morales y Políticas encargara hacer a Louis René Villermé sobre las condiciones de vida de las clases trabajadoras en $1840^{14}$, o el informe que presentó Charles Dupin sobre el trabajo de los niños también en el año $1840^{15}$, finalmente el Ministro de Comercio y Agricultura Laurent Cunin-Gridaine presentó un proyecto de ley que dio lugar a un enervado debate en la Asamblea ${ }^{16}$. Sus detractores quisieron paralizarlo alegando que esta ley supondría un enorme perjuicio para la industria y la economía del país, que era contraria a los intereses de los propios trabajadores porque se resentiría el salario que los niños podrían aportar a la familia, e incluso que afectaba tanto al principio de libertad de trabajo como a la autoridad paterna.

Frente a ello, se impusieron las voces humanitarias que defendían los argumentos de Legrand y otros filántropos, y quedó establecido que la libertad de trabajo debía quedar sujeta a los principios de humanidad y moralidad, y que era un abuso ilegítimo de la autoridad paterna exponer a los hijos a una muerte prematura o un daño permanente en su salud por el mero beneficio económico, debiendo en esos casos actuar el Estado como tutor. Bajo estos argumentos morales, en el año 1841 se promulgaba finalmente la primera ley obrera protectora del trabajo de los niños en Francia: la loi du 22 de mars 1841 relative au travail des enfants employés dans les manufactures, usines ou ateliers $^{17}$.

\footnotetext{
${ }^{14}$ VILLERME, L.R., Tableau de L'État physique et moral des ouvriers employés dans le manufactures de coton, de laine et de soie, Paris, 1840.

${ }^{15}$ Dupin, C., Du travail des enfants qu'emploient les ateliers, les usines et les manufactures, considéré dans les intérêts mutuels de la société, des familles et de l'industrie, Paris, 1840.

${ }^{16}$ Grigaut, M., Histoire du travail et des travailleurs, Paris, Librairie Delagrave, 1931, pp. 196-199, Dolleans, E. ET Dehove, G., Histoire du travail en France, mouvement ouvrier et législation sociale, vol. 1: Des origines à 1919, Paris, 1953, p.76, y Lefranc, G., Histoire du travail et des travailleurs, Paris, Flammarion, 1975, pp. 262-265.

${ }^{17}$ Heywood, C., Children in nineteenth-century France: Work, health and education among the "clases populaires”, Cambridge, 1988, pp.320-324, y GuIN, Y., "Au cœur du libéralisme: La loi du 22 mars 1841 relative au travail des enfants employés dans les manufactures, usines et ateliers", Deux siècles de droit du travail : L'histoire par les lois, Paris, 1998, pp. 29-44.
} 
La ley sólo era de aplicación en aquellas industrias o talleres de más de veinte obreros, como las primeras leyes inglesas, y sólo si utilizaban maquinaria de motor mecánico o a vapor, lo cual excluía de su aplicación a todos los jóvenes empleados en otro tipo de talleres domésticos y establecimientos de mediana o pequeña escala y menor peligrosidad. En las fábricas en las que era de aplicación, rebajó la edad mínima para ser contratado a los 8 años, y estableció limitaciones de hasta ocho horas en la jornada laboral de menores de 12 años, y de hasta doce horas en la jornada de jóvenes de 12 a 16, prohibiendo el trabajo nocturno a los menores de 13 años (salvo excepciones por reparaciones urgentes). También reconoció el descanso dominical y en días de fiesta para los menores, anticipándose algunos años a la ley de fábrica inglesa de 1847, y exigió la escolarización obligatoria y formación religiosa de los niños hasta los 12 años.

La norma previó un servicio de inspección para velar por su cumplimiento, compuesto por una serie de inspectores que de forma voluntaria y gratuita (sin ninguna obligación concreta) podrían trasladarse a los establecimientos fabriles acompañados de médicos, en su caso, para comprobar el respeto de las horas de trabajo e instrucción de los niños, y realizar reconocimientos médicos a los propios menores, vigilando porque se garantizase su salubridad y seguridad en las fábricas y en el uso de las máquinas. En caso de incumplimiento, las actas de los inspectores podrían utilizarse ante el juez de paz, aunque admitían prueba en contrario.

La ley también señalaba la necesidad de que se realizaran reglamentaciones específicas para regular el trabajo de los niños en trabajos insalubres y peligrosos. Pero en los años siguientes no sólo no llegaron a redactarse aún ese tipo de normas de desarrollo, sino que incluso fue difícil la aplicación de la propia ley en las industrias afectadas ${ }^{18}$.

Tras la Revolución social de 1848, en la que no hubo tiempo material para abundar en la cuestión de los niños o jóvenes trabajadores, los espíritus más humanitarios del gobierno formado bajo el reinado de Napoleón III volvieron a preocuparse por la situación de los mismos, abriendo un interesante debate parlamentario sobre el contrato de aprendizaje que culminó con la loi du 4 mars 1851 sur les contrats d'apprendissage. La finalidad principal de esta norma era extender la protección de la ley de 1841 a los jóvenes que, trabajando en talleres artesanales bajo la dirección de un maestro o artesano, no estaban amparados por ella ${ }^{19}$. A tal fin, se previeron asimismo para ellos

\footnotetext{
${ }^{18}$ SAITO, Y., "Le problème du travail des enfants en Alsace au XIXe siècle : l'industriel alsacien et la loi du 22 mars 1841", Histoire, économie \& société, n²5-2 (2006), pp.181-193.

19 Tholozan, O., "Le débat parlementaire de 1851 sur le contrat d'apprentissage ou la liberté contractuelle acclimatée", Cahiers de l'Institut Régional du Travail d'Aix-en-Provence, ${ }^{\circ} 9$ (avril 2001), Université de la Méditerranée, pp.207-222, у ChоғFAт, T., "La loi de 1851 sur l'apprentissage", Revue du Souvenir Napoléonien, n. 437 (oct-nov 2001), pp.31-35.
} 
ciertas condiciones de trabajo, relativas al alojamiento, comida y precio del mismo, y se estableció la limitación de la jornada laboral hasta diez horas para los menores de 14 años, y hasta doce para los comprendidos entre 14 y 16. La ley también prohibió el trabajo nocturno a menores de 16 años, y dejó abierta la posibilidad de que se permitiera a algunos de ellos el descanso dominical por cuestiones religiosas ${ }^{20}$.

Tras los inciertos resultados en la aplicación de estas leyes, la loi du 22 de mars $1841 \mathrm{y}$ la loi du 4 mars 1851, surgieron nuevas voces de denuncia sobre la situación de los niños en las fábricas, como la de Jules Simon con su L'ouvrier de huit ans (1867) que tuvo una enorme repercusión en la sociedad de su época. En la década de los sesenta, la problemática de la mujer trabajadora había comenzado también a ser seriamente debatida en Francia, debido fundamentalmente a su presencia masiva en algunos sectores $^{21}$. Ambas cuestiones dieron lugar a que la Asamblea francesa aprobara una nueva ley para proteger a los niños trabajadores, que por primera vez hacía asimismo una referencia específica a la protección de la mujer: la loi du 19 mai 1874 sur le travail des enfants et des filles mineures employés dans $l^{\prime}$ industrie ${ }^{22}$.

Bastante más extensa que la anterior, además de elevar a los 12 años la edad mínima para trabajar, reducir aún más la jornada laboral de niños y de las mujeres de hasta 21 años, reconocerles a ambos colectivos el descanso dominical y las fiestas, y prohibirles el trabajo nocturno, esta norma introdujo una nueva e importante medida de seguridad, al prohibir el trabajo de los mismos en las fábricas o trabajos señalados como insalubres o peligrosos (salvo reglamentación excepcional en contrario), y en particular en aquellos en los que se manipulara materias explosivas o en los que se prepara, destilara o manipulara substancias corrosivas, venenosas o perjudiciales para la salud.

La norma también abundaba en las medidas de higiene, limpieza u orden que debían tener las industrias para garantizar unas buenas condiciones de seguridad y salubridad, señalando por vez primera una serie de fábricas (con motores mecánicos, ruedas, correas, engranajes y cualquier otro aparato) en las que se tenían que adoptar especiales medidas de seguridad por su peligrosidad (aunque sin especificar qué tipo de medidas).

\footnotetext{
${ }^{20}$ WeSsBaCh, L.S., Child Labour Reform in 19th century France. Assuring the Future Harvest, Baton Rouge Lieu, Louisiana State University Press, 1989.

${ }^{21}$ Dubesset, M., Thibaud, F., ET Vincent, C., Quand les femmes entraient aux usines. Mémoire de maitrise, université de Paris VII, París, 1974, Stewart, M-L., Women Workers and the French State, Montréal, 1989, o Auslander, L. et Zancarini-Fournel, M.(éds.), Différence des sexes et protection sociale (XIXe-XXe siècles), Presses Universitaires de Vincennes, 1995.

${ }^{22}$ BourdeauX, M., "Nouvelle et périmée: la loi du 19 mai 1874 sur le travail des enfants et des filles mineures employés dans l'industrie", Deux siècles de droit du travail : L'histoire par les lois, Paris, 1998, pp. 45-60.
} 
Además, imponía la obligación a los patronos de velar por la moralidad y las buenas costumbres de sus trabajadores dentro de los establecimientos industriales.

Otros países como Luxemburgo, Bélgica o Dinamarca promulgaron leyes similares en años sucesivos para apartar o proteger a los niños y a las mujeres jóvenes del trabajo, y en particular del trabajo en las minas $u$ otros trabajos peligrosos ${ }^{23}$. En términos generales, la higiene quedaba garantizada con medidas de limpieza, ventilación, canalización de aguas o residuos, y encalado de las fábricas, mientras que la seguridad se afrontaba solo de manera preventiva con especiales normas sobre el uso de las máquinas, y las cada vez más importantes prohibiciones de ejercer determinados trabajos en sectores insalubres o peligrosos para los niños y las mujeres.

Casi veinte años después, respondiendo a la vorágine normativa que se vivió a mediados de la Tercera República por conciliar los intereses sociales y pacificar a la población, y tras haberse aprobado ya el derecho de asociación obrera en 1884 vino a redactarse una última ley en defensa de los niños y las mujeres ante el trabajo, la loi $d u$ 2 novembre 1892 sur le travail des enfants, des filles et de femmes dans les établissements industriels ${ }^{24}$. La ley seguía en la línea de elevar la edad mínima para trabajar (hasta los 13 años), reducir la jornada de trabajo de menores y mujeres, asegurarles el descanso dominical, prohibirles el trabajo nocturno, insalubre o peligroso, y exigir certificados médicos para el control de la salud de los trabajadores, además de las consabidas medidas de higiene (ventilación, limpieza, etc.), y de seguridad en el uso de las máquinas, que debían estar señaladas y no ser manipuladas por niños y mujeres estando en funcionamiento.

A la exclusión de los jóvenes y las mujeres de determinados trabajos, vino a sumarse un posterior decreto de 13 de mayo de 1893 que incorporaba las labores que pudieran exceder de sus fuerzas o fueran contrarios a la moralidad (por ejemplo, industrias donde se imprimieran grabados, pinturas o escritos que pudieran ser inmorales). Las industrias vedadas a estos colectivos por su especial insalubridad o peligrosidad finalmente se catalogaron en la loi du 28 décembre 1909 relative aux travaux interdits aux femmes et aux enfants ${ }^{25}$, con la que se puso fin a este primer periodo de simple prevención en materia de seguridad.

\footnotetext{
${ }^{23}$ Ramm, T., "Laissez-faire and State Protection of Workers", The making of labour law in Europe, London and New York, 2010, p.95.

${ }^{24}$ VIET, V., "Entre protection légale et droit collectif: la loi du 2 novembre 1892 sur le travail des enfants, des filles mineures et des femmes dans les établissements industriels", Deux siècles de droit du travail : L'histoire par les lois, Paris, 1998, pp.73-88.

${ }^{25}$ Heywood, C., Children in nineteenth-century France: Work, health and education among the "clases populaires, Cambridge, 1988, pp.326-331, y WeSSBACH, L.S., Child Labour Reform in 19th century France. Assuring the Future, Louisiana State University Press, 1989.
} 
Por su parte, España se sumaría finalmente a la legislación obrera protectora de los niños y las mujeres en la segunda mitad del siglo XIX, más de setenta años después que Gran Bretaña, y más de treinta años después que Francia. Es cierto que los estudios de médicos o higienistas denunciando las malsanas y peligrosas condiciones de vida de la clase trabajadora, y en particular de los niños y de las mujeres, fueron conocidos mucho antes, y que el "higienismo industrial" tuvo sus propios adalides en las figuras de médicos Pedro Felipe Monlau ${ }^{26}$, Joaquín Solarich ${ }^{27}$ o Francisco Méndez Álvaro ${ }^{28}$. Pero el primer proyecto de ley del Ministro de Fomento Manuel Alonso Martínez, que se presentó a las Cortes en octubre de 1855, tras los sucesos de la huelga general de Barcelona, nunca llegó a promulgarse, a pesar de que planteaba las medidas propias de la época, como la reducción de la jornada laboral para los niños, la prohibición de que trabajaran por la noche, y la exigencia de medidas de higiene, orden y disciplina a los dueños de los establecimientos para prevenir accidentes de trabajo ${ }^{29}$.

La tardía industrialización española, y el largo periodo de signo moderado con el que se gobernó el país tras las guerras carlistas, hicieron que estas cuestiones quedaran retrasadas en España hasta la formación del efímero gobierno de la Primera República. Sólo entonces consiguió aprobarse la primera ley sobre el trabajo en los talleres y la instrucción en las escuelas de los niños obreros, de 24 de julio de 1873, conocida como ley Benot en honor a su principal artífice ${ }^{30}$. Se trataba de una ley muy breve, que simplemente fijó la edad mínima para trabajar en los 10 años, estableciendo restricciones de jornada y la prohibición del trabajo nocturno para los niños y niñas de edades superiores hasta los 17 , aunque limitándolas a "los establecimientos en que se empleen motores hidráulicos o de vapor".

En cuanto a las concretas medidas de higiene y seguridad, la ley prohibía el trabajo de los niños en las industrias más peligrosas o insalubres, introducía la obligación de que todos los establecimientos industriales tuvieran un botiquín, y les obligaba asimismo a que celebraran contratos de asistencia con un médico cirujano, cuyo punto de residencia no podía exceder de diez kilómetros, para atender los accidentes de trabajo.

\footnotetext{
${ }^{26}$ MONLAU, P.F., Elementos de higiene pública o el arte de conservar la aalud de los pueblos, Madrid, 1847, o Higiene industrial ó ¿qué medidas higiénicas puede dictar el gobierno á favor de las clases obreras, Madrid, 1856.

${ }^{27}$ Véase la edición crítica sobre las obras de Monlau y SAlarich DE Jutglar, A., Condiciones de vida y trabajo obrero en España a mediados del s. XIX, Barcelona, 1984.

${ }^{28}$ AlCAide GonZÁlez, R., "Las publicaciones sobre higienismo en España durante el periodo 17361939”, Scripta Nova, n³7 (abril 1999), pp.32-54.

${ }^{29}$ Elorza, A., "El Proyecto de Ley de Alonso Martínez sobre el trabajo en la industria (1855)", Revista de Trabajo, no 27-28 (1969), pp. 253-483.

${ }^{30}$ Martínez PeÑas, L., "Los inicios de la legislación laboral española: la ley Benot", Revista Aequitas, $\mathrm{n}^{\mathrm{o}} .1,2011, \mathrm{p} .31$.
} 
Una nueva ley de 26 de julio de 1878, de trabajo peligrosos de los niños, completó a la anterior, dando respuesta a una problemática muy específica que indignaba a la opinión pública y fue denunciada ante las Cortes: la de los menores expuestos por sus propios padres o guardadores a los riesgos de espectáculos públicos u otras actividades relacionadas con la mendicidad o la vagancia ${ }^{31}$. La ley sólo iba dirigida a este sector de actividad y castigaba, elevando la acción a la categoría de delito, a quienes empleasen en este tipo de actividades ("acróbatas, gimnastas, funámbulos, buzos, domadores de fieras, toreros, directores de circo o otras análogas") a menores de 16 años que no fueran sus descendientes, o menores de 12 años en el caso de ser sus propios descendientes.

Insatisfechos con los resultados y pretendiendo incorporar mejoras, los anhelos de los reformadores sociales culminaron, sin embargo, con otra ley impulsada por el Ministro Eduardo Dato: la ley de 13 de marzo de 1900 sobre el trabajo de las mujeres y los niños, desarrollada por un posterior reglamento de 13 de noviembre de 1900. La norma ampliaba su aplicación a todos los centros industriales y mercantiles, quedando excluidos solamente los trabajos agrícolas o en talleres domésticos. Mantenía la edad mínima para trabajar en 10 años, aunque permitía que se contratara excepcionalmente a niños de 9 que acreditaran saber leer y escribir. Las limitaciones de jornadas eran de 6 horas en la industria y 8 en el comercio para niños de 10 a 14 años, y según dispusieran las llamadas Juntas locales y provinciales de reformas sociales para jóvenes de 15 a 18 y mujeres. Los menores de 14 tenían prohibido el trabajo nocturno, y los menores de 16 el trabajo subterráneo, peligroso, insalubre o que afectase a su moralidad. Además, se recogió por primera vez para ellos y las mujeres el descanso dominical ${ }^{32}$.

El artículo segundo de la ley, que remitía a las propuestas de las Juntas locales y provinciales la limitación de la jornada de trabajo de los jóvenes y las mujeres, se completó con el posterior Real Decreto de 26 de junio de 1902, que finalmente fijó dicha limitación en un máximo de 11 horas diarias o 66 semanales, excluyendo siempre los domingos.

\footnotetext{
${ }^{31}$ EspunY TOMAS, M. J., "Los niños y la mendicidad: explotación infantil y legislación histórica (18781912), V Congreso de Historia Social. Las figuras del desorden: heterodoxos, proscritos y marginados, Ciudad Real, 2005, pp.36 y ss, o EspunY Tomas, M. J., "Mendicidad infantil: Ley de mendicidad y vagancia de los menores de dieciséis años de 23 de julio de 1903" Iuslabor 4 (2005).

${ }^{32}$ Palomeque López, M. C., "Orígenes de la regulación del trabajo femenino en España: la Ley de 13 de marzo de 1900" en Cuadernos de Derecho del Trabajo 1-2 (1975-1976), pp. 223-271, NúÑEZ ORGAZ, A., "Gestación de la primera Ley de regulación del trabajo de la mujer (1883-1900)", El trabajo de las mujeres. Siglos XVI-XX. VI Jornadas de investigación interdisciplinar, Madrid, 1996. pp. 231-248, o ESPUNY TOMÁs, M.J., "La primera legislación social protectora de la mujer: una perspectiva comparada", Derecho y trabajo en el siglo XIX, Jaén, 2017, pp.108-116.
} 
Para clasificar los distintos establecimientos fabriles o comerciales, determinando cuáles estaban prohibidos por su peligrosidad, insalubridad o inmoralidad al trabajo de mujeres y niños, se redactaron nuevas normas como la ley de 21 de octubre de 1903, la ley sobre la protección de la infancia de 12 de agosto de 1904, que remitía a las anteriores, o la ley de 25 de enero de 1908 sobre industrias y trabajos prohibidos total o parcialmente a los menores y mujeres. Cabe señalar la especial preocupación de esta normativa por apartar a los menores de cualquier tipo de máquina que supusiera un riesgo, de trabajos de arrastre o elevación, y por supuesto de trabajos insalubres o con sustancias venenosas.

\section{La ampliación de la protección para todos: la prevención de la salud y seguridad del trabajador adulto en las leyes de fábrica del Reino Unido}

Es una obviedad decir que muchas de las disposiciones sobre higiene y seguridad contenidas en las primeras leyes protectoras de los niños y las mujeres (la obligación de ventilar y encalar los establecimientos, la limpieza de las máquinas en parado, la necesidad de tener un botiquín, etc.), eran beneficiosas indistintamente para todo tipo de trabajadores. Dejando a un lado medidas específicas (como los certificados médicos a los niños, o la prohibición de los trabajos peligrosos o insalubres a niños y mujeres), cuando un empresario acometía una mejora que tenía que ver con la edificación, la limpieza o la salubridad del establecimiento, podía mejorar las al mismo tiempo las condiciones de todos sus empleados y ello redundaba en la productividad de la fábrica, reduciendo las posibles bajas por enfermedad, sin que le generara ningún coste adicional.

Ese argumento, y otro mucho más importante, que era el mantenimiento de la salud pública frente a posibles contagios o epidemias que pudieran tener su foco en los establecimientos fabriles, pronto desdibujaron la línea irracional que distinguía a los menores y a las mujeres frente a los hombres en cuestiones de higiene y seguridad. Los estudios de médicos o higienistas achacando el origen de las enfermedades a las malsanas y peligrosas condiciones de vida de la clase trabajadora (hacinamiento, pobreza, humos de las máquinas, productos industriales tóxicos, etc.), se multiplicaron tras la promulgación de las primeras leyes obreras, creando una especial alarma social que permitió el desarrollo de disposiciones generales de carácter preventivo sobre estas cuestiones $^{33}$.

\footnotetext{
33 Soto CARmona, A., "La higiene, la seguridad y los accidentes de trabajo. España (1874-1936)", Revista Española de Derecho del Trabajo, nº23 (1985), pp.389-391, o BouRdelais, P., Les hygiénistes. Enjeux, modéles et practiques, Paris, 2011.
} 
La higiene y la seguridad se convirtieron, en consecuencia, en los dos temas principales que consiguieron trasladar el ámbito de aplicación de la ley obrera de carácter excepcional desde los grupos más débiles (menores y mujeres) al trabajador adulto, y ello ocurrió nuevamente con carácter previo en el Reino Unido. Atenderemos a continuación a las leyes que se dictaron con carácter general o transversal para todo tipo de industria y trabajadores en ese país, dejando a un lado, por su especialidad, las leyes o reglamentos específicos sobre sectores concretos, como la minería u otras industrias peligrosas o insalubres, que por su abundancia sería muy difícil compendiar en este artículo.

Podría decirse que la primera ley de carácter general sobre higiene en la industria promulgada en el Reino Unido, fue la llamada Sanitary Act de 1866, que pretendía refundir y superar las distintas disposiciones locales sobre limpieza o salubridad en las ciudades, incorporando una importante novedad: por primera vez, esta norma dejaba en manos de las autoridades sanitarias locales el control de la higiene en todas aquellas fábricas, talleres, almacenes o comercios, incluso familiares, que no estuvieran regulados por leyes de fábrica específicas, extendiendo a ellas sus disposiciones básicas sobre el tratamiento de las aguas y residuos, la limpieza, el encalado y la ventilación ${ }^{34}$. La norma incorporaba un apartado específico sobre su aplicación en Irlanda.

También es necesario hacer mención en este sentido a la Public Health Act de $1875^{35}$, una norma marco que ampliaba los poderes de las autoridades sanitarias locales en cuanto a la supervisión de alcantarillas, suministros y drenaje de aguas, calles, casas, alumbrado público, etc. Fundamentalmente pretendía evitar las construcciones de mala calidad y el hacinamiento derivado de la industrialización en las ciudades, y para ello se mantenían las facultades de las autoridades sanitarias locales, que debían trabajar con un oficial médico y un inspector de higiene, en el control de bodegas, talleres, almacenes y cualquier otro establecimiento comercial o industrial no sujeto a las leyes de fábrica.

No obstante, la ley que supuso un verdadero punto de inflexión en el desarrollo del higienismo y la seguridad en el Reino Unido, fue la ley de fábrica o Factory and workshop Act de 1878, un extensísimo texto que pretendía refundir y consolidar toda la normativa anterior, y que dedicó específicamente dos secciones de su articulado a unificar este tipo de disposiciones bajo las rúbricas "sanitary provisions" y "safety". Ambas secciones, dedicadas respectivamente a la higiene y la seguridad, fueron

\footnotetext{
${ }^{34}$ Michael, W.H., The Sanitary Acts: comprising the Sewage utilization Act, 1865, and the Sanitary Act, 1866, London, 1867, pp.57-99.

${ }^{35}$ Cunningham, W., And Glen, A., The Public Health Act, 1875, and the Law relating to Public Health, Local Government, and Urban and Rural Sanitary Authorities, Eighth Edition. Butterworths. Knight \& Co. London. 1876.
} 
completadas poco después por la ley de 1891, que fundamentalmente dejó la potestad última de control o supervisión de estas cuestiones a las autoridades sanitarias locales, relacionando ambas instituciones y poniendo fin a la duplicidad o posibles conflictos competenciales entre éstas y los inspectores de fábrica ${ }^{36}$.

Las disposiciones contenidas en la sección sobre higiene establecían, en primer lugar, que todas las fábricas y talleres debían mantenerse limpios (debiéndose limpiar o encalar al menos una vez cada catorce meses), y libres de los efluvios emanados de cualquier desagüe, colector de agua, inodoro, urinario, etc. No podían estar aglomeradas o superpobladas ("overcrowded"), y debían ventilarse de manera frecuente para eliminar gases, vapores, polvo y otras impurezas generadas por el proceso de fabricación (hubo normas posteriores, como la de 1883, destinadas a fijar los niveles de calor o humedad excesivos en las salas de trabajo, particularmente en la industria textil). Además de estar apartados de las máquinas e industrias peligrosas en atención a leyes anteriores, esta ley también establecía que ningún niño, joven o mujer, podían ser empleados en el hilado en húmedo o en procesos en los que hubiera escape de vapor.

La enmienda de 1891 amplió la aplicación de estas disposiciones a todo tipo de talleres y lavanderías ( "workshops and laundries"), hasta entonces bajo el ámbito de la Public Health Act de 1875, y estableció que los inspectores de fábrica debían actuar en colaboración con las autoridades sanitarias locales, a las que tenían que dar noticia de los incumplimientos de la ley y de sus actuaciones. Las autoridades sanitarias locales y sus oficiales (médico e inspector de higiene) podían entrar en cualquier momento en los establecimientos para inspeccionar o supervisar los procedimientos, y la Secretaría de Estado podía instar a los inspectores a adoptar medidas especiales para lograr el cumplimiento de la ley en aquellas industrias o talleres donde no se observase.

Si un inspector consideraba que una fábrica podía estar afectada con cualquier otra molestia o riesgo para la salud de las personas no previsto en la norma (teniendo en cuenta también las reglas especiales previstas para cada industria, minera, peligrosa o insalubre, comercial, panadera...), se le exigía que acudiera a las autoridades sanitarias locales para que se pronunciaran sobre la cuestión. A tal objeto, el inspector podía llevar a la fábrica o taller a un sanitario, inspector de ruidos, o cualquier otro oficial que considerara conveniente. El especialista debía redactar un informe con las recomendaciones necesarias, que se trasladarían al propietario del establecimiento instándole a su cumplimiento.

\footnotetext{
${ }^{36}$ RedgraVe, A., AND ReDgrave, J., The factory and workshop acts 1878 to $1891,5^{\text {th }}$ ed, London, 1893 , pp.2-16.
} 
En cuanto a la sección dedicada a la seguridad o "safety", aún más extensa que la de higiene, comenzaba con una primera disposición relativa a la obligación de vallado $\mathrm{y}$ señalización de maquinaria especialmente peligrosa como grúas o elevadores, montacargas, ruedas hidráulicas o conectadas a cualquier otro medio de acción mecánica, máquinas de vapor, engranajes y, en general, cualquier máquina que pudiera producir algún daño a las personas. Este vallado debía mantenerse de forma eficiente, y debía utilizarse especialmente cuando la maquinaria estuviera en movimiento, recogiéndose la prohibición ya prevista en normas anteriores de que los menores y mujeres no pudieran limpiar ni trabajar en máquinas en movimiento, ni entre las partes fijas y transversales de cualquier maquinaria de acción automática.

Para las nuevas fábricas con más de cuarenta empleados que se construyeran en adelante, se exigió además un nuevo certificado de la autoridad sanitaria local acreditando que el establecimiento contaba con los adecuados medios de evacuación y escape en los sótanos o plantas por debajo de la planta baja. En cumplimiento de la Public Health Act de 1875, que volvía a citarse como norma de referencia, las autoridades sanitarias deberían inspeccionar el resto de las fábricas con más de cuarenta empleados, y redactar un informe indicando a los propietarios como establecer o mejorar dichas vías de escape, poniéndoles una fecha máxima de cumplimiento. En caso de discrepancia con las autoridades sanitarias, los propietarios podían recurrir al arbitraje y, en última instancia, a los tribunales intermedios, no locales (los "county court").

De la misma manera, y paso a traducir literalmente la disposición octava de esta sección, "cuando la Secretaría de Estado certifique que en su opinión cualquier maquinaria o proceso o medio particular de trabajo manual utilizado en una fábrica o taller (al margen del taller doméstico), es peligroso o lesivo para la salud o peligroso para la vida o cualquier miembro del cuerpo, ya sea en general o en el caso de mujeres, niños o cualquier otra clase de persona, o que la provisión de aire fresco no es suficiente, o que la cantidad de polvo generado o inhalado en la fábrica o taller es peligroso o lesivo para la salud, el inspector jefe debe ofrecer al empleador de la fábrica o taller un informe por escrito, bien proponiéndole medidas especiales o bien requiriéndole la adopción de medidas especiales que a su juicio sean razonablemente factibles para solventar las necesidades del caso".

Es decir, más allá de lo legislado en concreto, se volvía a dejar en manos de las autoridades, como ya se había hecho en el caso de la higiene, el establecimiento de reglas especiales ("special rules") en atención a los riesgos detectados en la seguridad de cada establecimiento, que eran de obligado cumplimiento. De hecho, la ley fijaba un plazo de veinte días desde la recepción del informe para que se estableciesen las 
medidas recomendadas, aunque los propietarios afectados podían recurrir ante la Secretaría de Estado y someterse a un arbitraje en caso de discrepancia, e incluso acudir ante los tribunales, al igual que en el caso de las medidas de higiene especialmente recomendadas. Una vez terminado el proceso y siendo ejecutivas las medidas, estas debían fijarse en copias impresas en lugares visibles de la fábrica o taller para que pudieran ser conocidas por todos los empleados, y en caso de incumplimiento entraba en funcionamiento el régimen sancionador.

La última disposición contenida en la sección de seguridad de esta ley, desde su expresa adición en 1891, fue la prohibición de contratar a una mujer sabiendo ( "knowingly") el empleador que había dado a luz en menos de cuatro semanas. La norma, muy breve y sin apenas desarrollo, solo establecía que los dueños de las fábricas no podían permitir conscientemente que una mujer fuera contratada en las cuatro semanas después del parto, para proteger su salud y la de su hijo. No obligaba a la baja maternal, ni responsabilizada de ella al empleador, ni decía nada de la reserva del puesto de trabajo o de la remuneración de la mujer. Estas dificultades, y la vaguedad con la que la disposición estaba redactada, entorpecieron sin duda su aplicación en los años siguientes a su promulgación (al menos hasta que en 1911 se aprobara una Insurance Act que incorporaba una prestación de maternidad). No obstante, hay que reconocerle el mérito de que, tras la ley alemana de 1878, la inglesa fue la segunda ley europea en afrontar el problema de la maternidad.

La posterior ley industrial de carácter general o "de consolidación” que superó a la de 1878, la Factory and Workshop Act de 17 de agosto de 1901, incorporó prácticamente todas las disposiciones anteriores, aunque desarrolló gradualmente algunas de sus características, fortaleció su contenido, y añadió algunas previsiones más, terminando de perfilar las líneas fundamentales del higienismo y la seguridad antes de la Primera Guerra Mundial ${ }^{37}$. Así, por ejemplo, esta ley aumentó la maquinaria peligrosa susceptible de especial vallado, tratando de hacer este cercado más eficiente con normas específicas, y regulando incluso en las fábricas de nueva construcción la distancia que debía haber entre las máquinas, y la distancia entre las máquinas y las personas. Otra novedad que introdujo para garantizar un control más eficaz de la maquinaria, fue la obligación de que el jefe de ingenieros o jefe de máquinas de cada fábrica examinara las mismas cada catorce días, debiendo mostrar sus registros a los inspectores ${ }^{38}$.

\footnotetext{
${ }^{37}$ Hutchins, B.L., AND HARrison, A., A history of factory legislation, $2^{\circ}$ ed., London, 1911, pp.245-252, y Thomas, M.W., The early factory legislation: a study in legislative and administrative evolution, Leigh on Sea, 1948, p.249.

${ }^{38}$ An Act to consolidate with amendments the Factory and Workshop Acts, London, 1901.
} 
De la misma manera, intentaron mejorarse las disposiciones sobre ventilación, que debía poder hacerse en cada sala y no de forma general; drenaje de líquidos, con medidas de especial precipitación que impidieran que los líquidos dejaran el suelo húmedo; temperatura y humedad, añadiéndose una tabla en el anexo de la ley con los límites máximos de humedad por industria, y una tabla para medir la temperatura que debía cumplimentarse en cada establecimiento. Para el caso del hacinamiento, se reguló específicamente el espacio que debía haber por trabajador, según las circunstancias de la industria, y se obligó a los propietarios a indicar exactamente cuántas personas trabajaban en cada sala de la industria o taller. Si algunas de las salas se utilizaban como habitación por las noches, también debía claramente indicado, procurando el adecuado alojamiento de los trabajadores y su separación por sexos.

Una mejora específica que se incorporó a la normativa en relación a una más rápida evacuación o escape de las fábricas fue la obligación de que las puertas entre salas o del exterior permanecieran sin bloquear durante las horas de trabajo, y en el caso de las fábricas de nueva construcción que se utilizaran puertas correderas ("sliding doors"). Cada industria debía contar con un plan de evacuación específico certificado por el consejo sanitario del distrito.

El concejo sanitario de cada distrito se convirtió, junto a las autoridades sanitarias locales y sus oficiales, en el principal órgano de control de estas medidas de higiene y seguridad para hacer más eficiente también la ejecución de las mismas. Bajo su autoridad quedaron los inspectores de fábrica, menos numerosos, y los médicos o cirujanos encargados de certificar la salud de los trabajadores, y en especial de los menores y las mujeres, como sabemos. Por su parte, la Secretaría de Estado conservaba sus competencias para definir reglas de especial cumplimiento según el tipo o carácter de cada industria, y en caso de tener que acudir ante un juez, se prescribió asimismo que éste no podía estar relacionado en ningún caso, ni directa ni indirectamente, con la industria en cuestión ${ }^{39}$.

Medidas sanitarias y de seguridad específicas se contemplaron en la sección quinta de la ley para determinadas industrias, como las de algodón, panaderías, lavanderías, muelles, construcción de edificios o vías del ferrocarril. Y, para finalizar, cabe destacar una sección sexta en la que la norma amplió las potestades del consejo sanitario de cada distrito para el control de la salud de los trabajadores externos o "a domicilio", un sector que apenas se había regulado en la norma anterior. Para una mejor protección de su salud a los efectos de enfermedades contagiosas o epidemias, se obligó a los

\footnotetext{
${ }^{39}$ HUTChINS, B.L., AND HARRISON, A., A history of factory legislation, $2^{\circ}$ ed., London, 1911, p.245 y Henriques, U.R., The early Factory Acts and their enforcement, London, 1971.
} 
propietarios a elaborar listados de este tipo de trabajadores y sus lugares de trabajo, para que los oficiales pudieran inspeccionarlos, al igual que a los talleres domésticos.

\section{Leyes de higiene y prevención de la seguridad para todos los trabajadores en Francia y en España}

La resistencia de los industriales o empresarios franceses a adoptar nuevas medidas de higiene y seguridad para todos los trabajadores por los costes que les podrían generar, fueron siendo vencidas poco a poco a la vista de modelos extranjeros, como el más arriba descrito modelo inglés, o los modelos prusiano y belga. Estos países también habían comenzado a redactar tempranas normas sobre salud y seguridad en el trabajo, como la ley de comercio prusiana de 1845 que regulaba las actividades peligrosas, o los decretos belgas que desde 1849 a 1886 obligaban a los empresarios, especialmente en las industrias peligrosas o insalubres, a detallar las medidas adoptadas en prevención de salud y seguridad antes de darles el permiso de apertura ${ }^{40}$.

En la propia Francia, empresarios como Frédéric Engel-Dollfus, que creó la Association pour la prévention des accidents de machine en 1867, y trató de mejorar continuamente la condiciones de trabajo de los obreros en sus fábricas, inspiraron a otros empleadores $\mathrm{y}$ asociaciones a acometer medidas de higiene y seguridad, y reavivaron el debate político junto con los higienistas ${ }^{41}$, dando lugar a que, tan solo un año después de la aprobación de la loi du 2 novembre 1892, protectora de los menores y las mujeres, se promulgara la loi 12 juin 1893 sur l'hygiène et la sécurité des travailleurs dans les industries, que por primera vez introducía al trabajador adulto entre los sujetos susceptibles de protección.

La ley de 12 de junio de 1893 fue el resultado final de una larga trayectoria, que ya iniciara el diputado Lookroy con una proposición presentada a la Asamblea en 1889, seguida por otra proposición posterior de Félix Faure de 1890. Tras intensos debates e informes, finalmente fue aprobada por ambas cámaras en junio de 1893, y desde entonces ha sido considerada por la historiografía el punto de partida de toda la reglamentación francesa sobre higiene y seguridad ${ }^{42}$.

\footnotetext{
${ }^{40}$ Ramm, T., "Laissez-faire and State Protection of Workers", The making of labour law in Europe, London and New York, 2010, pp.103-104.

${ }^{41}$ BoIsSelier, J., Naissance et évolution de l'idée de prévention des risques professionnels: Petite histoire de la réglementation en hygiène, sécurité et conditions de travail, París, 2004.

${ }^{42}$ LAfARGE, P., "Évolution de la réglementation relative à l'hygiène et à la sécurité des travailleurs", Travail et sécurité, avril 1949, p.5, Chaumette, P., "Le comité d'hygiène, de sécurité et des conditions de travail et le droit de retrait du salarié", Droit social, nº, juin 1983, pp.425-433, LE GoFF, J., Du silence à la parole. Une histoire du droit du travail des anées 1830 á nous jours, Rennes, 2004, pp.214-215, BOISSELIER, J., Naissance et évolution de l'idée de prévention des risques professionnels: Petite histoire
} 
El ámbito de aplicación de esta norma se amplió a todo tipo de establecimiento industrial, no sólo los consideradores insalubres o peligrosos, y a todos sus trabajadores. Quedaban excluidas las minas o canteras, que contaban con sus propias reglamentaciones, los establecimientos comerciales, y los talleres familiares, aunque éstos últimos también podían ser objeto de inspección si tenían una caldera de vapor o motor mecánico, o si el trabajo realizado en ellos estaba clasificado como peligroso o insalubre. Sobre las industrias afectadas, el artículo segundo imponía un deber general de limpieza, obligando al propietario a proporcionar "las condiciones higiénicas y sanitarias necesarias para la salud del personal".

Las medidas concretas de protección y seguridad, especialmente en lo que se refería a la limpieza de los locales, ventilación, iluminación, agua potable, drenaje de líquidos, expulsión de polvo o vapores, y la evacuación contra incendios, se encomendaron a reglamentos posteriores que la Administración debía redactar con el aviso o consejo de un comité asesor de artes y manufacturas ("comité consultatif des arts et manufactures"), y con el visto bueno del comité consultivo de higiene pública de Francia ("comité consultatif d'hygiène publique de France").

De lo que sí se ocupó la ley fue de encomendar su aplicación y la de sus reglamentos de desarrollo a los inspectores de trabajo, regulando el procedimiento de inspección y obligándoles a presentar informes anuales sobre las industrias de sus respectivas circunscripciones, que podrían ser utilizados por el Ministerio de Comercio e Industria para ordenar mejoras. Asimismo, determinó las sanciones para los jefes de industria, directores, gerentes o responsables que infringieran sus disposiciones, una vez juzgados por los tribunales correspondientes de primera instancia, así como la de los reincidentes, que debían ser juzgados por tribunales correccionales en el ámbito penal. Si tras haber sido condenados y multados, los responsables continuaban sin implementar las medidas de seguridad o salubridad en el tiempo ordenado por la sentencia, podía llegar a ordenarse incluso el cierre del establecimiento.

El principal reglamento que se redactó para poner en vigor esta ley, fue el aprobado por decreto de 10 de marzo de 1894. Se trataba de un instrumento meramente técnico que se ocupó fundamentalmente de prescribir normas de cercado y señalización de maquinaria peligrosa como montacargas o elevadores; prevenir los riesgos de las máquinas e instalaciones eléctricas, de la que quedaron apartados especialmente los menores y las mujeres; disponer que se ventilara y que se evacuaran adecuadamente todo tipo de polvos o vapores producidos durante el proceso de fabricación, en atención a las recomendaciones de los higienistas sobre los daños que éstos podían producir en la

de la réglementation en hygiène, sécurité et conditions de travail, París, 2004, pp.16-24, o Moriceau, C., Les douleurs de l'industrie. L'hygiénisme industriel en France 1860-1914, Paris, 2009, pp.21-24. 
salud; y velar por la seguridad de los trabajadores en el edificio, regulando lo relativo a escaleras, pozos, escotillas, andamios o evacuación. Los temas y soluciones coincidían en líneas generales con los de la legislación británica.

Junto a este reglamento de carácter general, no tardaron en aparecer otros específicos según el tipo de trabajador, industria o materia, como el reglamento de 31 de julio de 1894 que ampliaba las protección de menores y mujeres frente al trabajo en industrias peligrosas o insalubres; el decreto del 29 de junio de 1895, que regulaba y protegía a los obreros que trabajaran con arsenito de cobre en las llamadas fábricas verdes de Schweinfurt; el decreto de 18 de julio de 1902, que limitaba el uso de plomo blanco en trabajos de pintura; o el decreto de 21 de noviembre de 1902, que regulaba el uso del estaño en la industria de cerámica.

Ahora bien, mientras otros proyectos de reglamentos específicos se iban presentando y estudiando por la Asamblea, con el apoyo de informes y estudios de químicos o higienistas, la siguiente norma de interés fue la loi du 11 juillet 1903, que vino a completar las disposiciones de la anterior ley de 12 de junio de 1893, extendiendo sus disposiciones a los establecimientos comerciales, así como a los teatros, circos o cualquier otro establecimiento similar que utilizara aparatos mecánicos, e incorporó alguna otra novedad digna de mención ${ }^{43}$.

Entre los principales logros de esta norma, además de extender a los establecimientos comerciales su ámbito de aplicación, puede señalarse la adición en el propio cuerpo de la ley de algunas medidas específicas en desarrollo del deber general de limpieza y seguridad contenido en el anterior artículo dos de la norma de 1893. El resto de prevenciones concretas de higiene o seguridad siguieron dejándose al desarrollo reglamentario, con una importante modificación procedimental que, en contrapartida, las asociaciones patronales consiguieron aprobar en el Senado, defendida por Morel, y que se introdujo finalmente en el artículo sexto: el aviso formal o "mise en demeure" al empresario como requisito necesario y previo a la apertura de cualquier proceso judicial.

El aviso formal era un escrito que el inspector tenía que presentar debidamente firmado y sellado en registro público, señalando las contravenciones específicas a los reglamentos que hubiera detectado en cada industria. De este aviso formal debía darse traslado al propietario o jefe de la industria, al que se le concedía además un plazo de quince días para reclamar ante el Ministerio de Comercio e Industria, dejándose en suspenso la aplicación de la advertencia o amonestación hasta que se resolviese su

\footnotetext{
${ }^{43}$ BRIAT, M.E., La réforme de la procédure de la mise en demeure organisée par la loi du 12 juin $1893-$ 11 juillet 1903 sur l'higiéne et la sécurité des travailleurs, Paris, 1910.
} 
recurso. En definitiva, un mecanismo muy útil para dilatar y entorpecer al máximo la aplicación de las disposiciones específicas sobre higiene y seguridad en el trabajo, que quedaron enredadas en este procedimiento y en muchas ocasiones incumplidas por los empresarios $^{44}$.

A pesar de ello, siguieron redactándose reglamentos como el aprobado en desarrollo de la ley de 1903 por Decret du 29 novembre 1904, relatif á l'hygiène et á la sécurité des travailleurs; u otros reglamentos específicos como el de 28 de julio de 1904 sobre el alojamiento del personal dentro de las industrias, el de 15 de julio de 1904 ampliando la protección en el uso del plomo blanco, el de 4 de abril para las lavanderías o talleres de lavado, el de 11 de julio de 1907 sobre la seguridad de los trabajadores en industrias que utilizaran electricidad, el de 7 de octubre de 1907 para prevenir accidentes causados por máquinas de vapor, el de 3 de abril de 1908 para industrias con riesgo de envenenamiento por plomo, el de 15 de diciembre de 1908 sobre trabajos con aire comprimido, el de 22 de agosto de 1910 previniendo la infección por ántrax, el de 8 de octubre de 1911 regulando el bocasoplado en vidrierías, el de 12 de octubre de 1912 sobre el uso de cemento fraguado rápido, los onces decretos de 11 de julio de 1913 con reglas específicas para determinados riesgos en la industria (plomo, electricidad, aire comprimido ...), etc.

Por lo que respecta al caso español, más allá de las disposiciones de la ley Benot de 24 de julio de 1873 respecto a los niños y mujeres, la legislación obrera apenas lograba despegar por las cuestiones más arriba aludidas. Sin apenas industria y con una situación política muy convulsa, tras la corta experiencia de la Primera República hubo otro claro parón en la legislación proteccionista. La ley Benot preveía cierto desarrollo reglamentario en cuestiones de higiene y seguridad que nunca llegó a producirse, y encomendaba a los "jurados mixtos" la vigilancia de su cumplimiento. Pero en la práctica, ni se abundó en el perfeccionamiento de la misma (a excepción de la antes citada ley de 1878 que prohibía a los menores los trabajos de acrobacia o espectáculos peligrosos), ni se regularon los órganos de inspección, por lo que la norma quedó en papel mojado.

Al margen de ello, la regulación acerca de la higiene y seguridad en el trabajo evolucionaba de manera muy lenta y parcial en España, a través de reglamentos específicos para industrias peligrosas, que contenían medidas particulares y meramente preventivas, como las que ya se venía dictando en algunas ordenanzas del Antiguo Régimen, o las que se comenzaban a incorporar en la legislación extranjera. En este sentido, antes de que se promulgara la ley Benot de 1873, ya se habían aprobado en la

\footnotetext{
${ }^{44}$ BRIAT, M.E., La réforme de la procédure de la mise en demeure organisée par la loi du 12 juin $1893-$ 11 juillet 1903 sur l'higiéne et la sécurité des travailleurs, Paris, 1910, pp.10-19.
} 
España liberal, por ejemplo, una Orden de 19 de junio de 1861 que regulaba el trabajo en los hornos de cal y de yeso, una Orden de 11 de diciembre de 1863 que establecía medidas específicas de seguridad en los talleres de fundición, o el Decreto de 29 de diciembre de 1868 sobre el trabajo en las minas, que contenía asimismo medidas de prevención de riesgos.

El diputado Manuel Danvila Collado, acusando la lentitud y el tedio con el que en este país se acometían las reformas necesarias para procurar el progreso, presentó varias proposiciones de ley de carácter social al abrirse una nueva legislatura en abril de 1877 , entre las que se contaba una interesante proposición "sobre establecimientos insalubres, peligrosos e incómodos"45. Al justificar su presentación al Congreso, afirmaba que seguía una línea ya iniciada por el propio Ministerio de Fomento dieciséis años atrás: "cabe la gloria al Ministerio de Fomento de haber iniciado en 1861 un proyecto de ley parecido al que hoy se presenta; pero pasado al Ministerio de la Gobernación, tropezó con la dificultad que ofrece la clasificación científica de estos establecimientos; y así es que en diez y seis años no se ha hecho nada sobre el particular" ${ }^{26}$. Su proposición ni siquiera llegó a ser aprobada por las Cortes, quedando olvidada en algún cajón a la espera de tiempos mejores.

La creación de la Comisión de Reforma Sociales cuando el reformista Segismundo Moret llegó al Ministerio de la Gobernación, en virtud de un Real Decreto de $1883^{47}$, sirvió de especial revulsivo sobre la cuestión. Una de las prioridades de la comisión, según su propia norma fundacional, era "preocuparse de la higiene, salubridad y seguridad en los talleres; así como del cuidado y la higiene de los barrios obreros". No en vano, aunque la mayoría de los miembros integrantes de la misma eran juristas, les seguían en importancia los médicos (Federico Rubio, Carreras González y Alberto Bosch), que se preocuparon particularmente de introducir estos temas. Para afrontarlos, la primera medida de este organismo fue la realización de un estudio de carácter nacional sobre las condiciones de vida de las clases trabajadoras, a través de encuestas que, además de otras cuestiones (trabajo de menores, mujeres, descansos, etc.), se ocupaban específicamente de las enfermedades y los riesgos laborales.

\footnotetext{
${ }^{45}$ Diario de Sesiones de Cortes, $\mathrm{n}^{\circ}$ 3, 27-04-1877, Apéndice 23.

${ }^{46}$ Diario de Sesiones de Cortes, $\mathrm{n}^{\circ} 17,19-05-1877, \mathrm{p} .297$.

${ }^{47}$ Palacio Morena, J.I., La institucionalización de la reforma social en España (1883-1924). La Comisión y el Instituto de Reformas Sociales, Madrid, 1988, Calle VelasCo, M.D. de la, La Comisión de Reformas Sociales: 1883-1903. Política social y conflicto de intereses en la España de la Restauración, Madrid, 1989, o García González, G., "Los inicios del reformismo social en España: la primera legislación social y la comisión de reformas sociales", Revista Gaceta Laboral, 14, n² (2008), pp.215-270.
} 
A las conclusiones de este análisis oficial sobre la precariedad e inseguridad en el trabajo, siguieron otros estudios específicos acerca de los daños de la industria textil sobre los trabajadores, o sobre las deficientes condiciones de higiene y seguridad en la mayoría de los oficios (informes sobre los riesgos del trabajo de la madera, el curtido de pieles, el teñido de telas, trabajos con cloro, plomo y otros elementos insalubres, etc.), y en particular en lo referido a los menores y las mujeres.

Las voces que pedían una intervención pública para prevenir los riesgos sobre la salud y la seguridad de los obreros se multiplicaron, promoviéndose algunos avances legislativos que dejaban vislumbrar el comienzo de un importante cambio conceptual, la defensa de la reparación más allá de la mera prevención de riesgos. Ejemplo de ello fue la ley de 11 de junio de 1886, aprobando el pliego de condiciones de la contratación pública, que por vez primera obligaba en España a un empleador, en este caso el contratista de obra pública, a asegurar la vida de sus operarios para todos los accidentes que dependieran directamente del trabajo, salvo los causados por negligencia, ignorancia o temeridad del propio obrero ${ }^{48}$. También debemos mencionar el Real Decreto de 11 de enero de 1887, por el que se creaba el Asilo de Inválidos del Trabajo de Vista Alegre; o el Real Decreto de 15 de julio de 1897, aprobando el reglamento de policía minera que venía a completar la ley de $1868^{49}$.

Sin embargo, habrá que esperar al conjunto de reformas regeneracionistas impulsadas por el Ministro de Gobernación Eduardo Dato a comienzos de siglo ${ }^{50}$, entre las que se contaba la ley de 13 de marzo de 1900 sobre el trabajo de las mujeres y los niños, y una novedosa ley de accidentes de trabajo de 30 de enero de 1900, para que finalmente comenzara a acometerse en España un regulación de carácter integral sobre la higiene y seguridad en el trabajo, incorporándose tanto medidas preventivas similares a las que venían desarrollándose desde hacía tiempo en otros países industrializados, como una nueva regulación reparadora o indemnizatoria de los accidentes de trabajo y las enfermedades profesionales que supuso un cambio trascendental en la consideración jurídica de la responsabilidad de las partes contratantes y el riesgo profesional, pero que, como dijimos en la introducción, queda al margen del objeto de este estudio.

Centrándonos aquí exclusivamente en las medidas de carácter preventivo, la ley de 13 de marzo de 1900 sobre el trabajo de las mujeres y los niños, y su posterior reglamento de desarrollo, incorporaron a la legislación española mayores limitaciones del trabajo de

\footnotetext{
${ }^{48}$ MARTín VALVERDE, A. (coord.), La legislación social en la historia de España. De la revolución liberal a 1936, Madrid, 1987, p.293.

${ }^{49}$ MARTín VALVERDE, A. (coord.), La legislación social en la historia de España. De la revolución liberal a 1936, Madrid, 1987, p.294

${ }^{50}$ Espuny i TomÁs, M.J., “Eduardo Dato y la legislación obrera”, Historia social, no 43, 2002, pp.3-14.
} 
éstos en industrias peligrosas e insalubres, como el resto de los países europeos ${ }^{51}$. Se les prohibieron así los trabajos subterráneos (en minas, canteras, túneles o alcantarillados), relacionados con materias inflamables, y en todas aquellas industrias que fueran calificadas como peligrosas o insalubres por normativa posterior, así como los trabajos de agilidad, equilibrio, fuerza o dislocación en espectáculos públicos $\mathrm{y}$, como particularidad española, también en las ocupaciones "de tal naturaleza que puedan herir su moralidad". Además, las mujeres y los menores quedaron apartados de la limpieza de motores y piezas de transmisión mientras estuviera funcionando la maquinaria, aunque, a diferencia de otros países, no se estableció aquí la necesidad de vallado, cercado o señalización de maquinaria.

Tampoco se prescribió todavía nada concreto sobre limpieza, encalado, ventilación, expulsión de humos, gases o polvos, drenaje de líquidos, hacinamiento o medidas de evacuación relacionadas con las edificaciones... Se estableció la absoluta obligación de mantener una separación completa de las personas de diferente sexo que no pertenecieran a la misma familia en sus alojamientos, y a ser posible en las salas de trabajo, velando nuevamente más por la moralidad que por la higiene o salubridad. Pero la determinación de las empresas peligrosas o insalubres, y todas las demás cuestiones específicas de higiene y seguridad se dejaron en el ámbito de la competencia y análisis de las Juntas provinciales, en las que debía haber un vocal técnico designado por la Real Academia de Medicina para ello. Cuando en la fábrica o taller hubiese motores mecánicos, o bien fuera considerada peligrosa o insalubre, el reglamento de 13 de noviembre de 1900 determinó asimismo que el Delegado del gobierno podía imponer medidas concretas de higiene y salubridad.

Ese mismo reglamento apremiaba a que el gobierno clasificara las industrias y trabajos que debían considerarse peligrosos e insalubres a los efectos de la ley "en el plazo más breve que sea posible". Sin embargo, dicha clasificación no fue aprobada hasta el Real Decreto de 25 de enero de 1908 de industrias y trabajos que se prohíben total o parcialmente a los niños y a las mujeres menores de edad, distinguiéndose, ya sí de forma muy exhaustiva, entre las industrias con riesgo de intoxicación por vapores o polvos nocivos (abonos, arsénico, ácido fluorhídrico, amoniaco, azufre, cloro, etc.), las industrias con riesgo de explosión e incendio (con celulosas, éteres, petróleo, etc.), las que podían suponer exposición a enfermedades o estados patológicos especiales (mataderos, pieles, minerales, papelerías, uso de cal, cemento, etc.), o las que suponían unas condiciones de trabajo especialmente duras por el esfuerzo o peso de materiales de arrastre o elevación. Ese mismo año, se promulgaba también un peculiar Real Decreto

51 EspunY TOMÁs, M.J., "La primera legislación social protectora de la mujer: una perspectiva comparada", Derecho y trabajo en el siglo XIX, Jaén, 2017, pp.108-116. 
de 18 de noviembre de 1908, para regular el trabajo de los menores de 14 años a bordo de barcos de pesca.

Entre tanto, se seguía avanzando paralelamente en las medidas de prevención y de reparación de los accidentes o los riesgos en el trabajo para todo tipo de trabajadores e industrias, no sólo el de los menores y mujeres en las industrias peligrosas e insalubres, a raíz de la ley sobre accidentes de trabajo de 30 de enero de $1900^{52}$. En cuanto a las medidas específicas de prevención, que aquí nos interesan, el artículo séptimo de esta norma ordenaba a la llamada Junta técnica de previsión de los accidentes de trabajo (compuesta por tres ingenieros y un arquitecto) la redacción de un catálogo de mecanismos para impedir los accidentes de trabajo, que resultó aprobado por el propio Eduardo Dato mediante Real Orden de 2 de agosto de $1900^{53}$.

El catálogo de mecanismos preventivos del año 1900 tenía un amplio alcance y contenido para todo tipo de ocupaciones. Proponía medidas específicas en el ámbito de los talleres, fábricas o canteras; en el de la construcción en general y la construcción de edificios en particular (andamios, zanjas y cimentación, alcantarillado, barandillas, aparatos, previsión y evacuación de incendios...); en el de la minería (con particular atención a la seguridad y ventilación subterránea); en el de la producción y transporte de energía eléctrica (medidas de aislamiento...); y en el de los almacenes y depósitos, donde recomendaba, por ejemplo, utilizar cajas de resistencia o seguridad para envasar materiales peligrosos y nocivos.

Quedándonos en el ámbito más general de los talleres, fábricas o canteras, distinguía a su vez entre las medidas de prevención de riesgos o seguridad, y las medidas de higiene. Las primeras se dividieron a atención a los establecimientos que utilizaran motores mecánicos, elementos o mecanismos de transmisión (correas, cables, engranajes, escaleras con fiadores...), máquinas auxiliares y operadoras (donde se proponían cercos, forros o topes como en la legislación europea de referencia), o las canteras. Las medidas de higiene incorporaron, por su parte, recomendaciones particulares de ventilación o purificación del aire, "baños especiales de taller", o "colocación" de líquidos y sustancias peligrosas (refiriéndose probablemente a su drenaje o evacuación), además de mantener la necesidad del botiquín y camillas en los establecimientos.

\footnotetext{
52 Alonso Olea, M., "El origen de la Seguridad Social en la Ley de Accidentes de Trabajo de 30 de enero de 1900", Revista del Ministerio de Trabajo, n42 (2000), pp.21-30, o García González, G., "La recepción de la doctrina del riesgo profesional en el ordenamiento jurídico español: la ley de accidentes de trabajo de 1900 y su aplicación por la primera jurisprudencia", Derecho y trabajo en el siglo XIX, Madrid, 2017, pp.196-199.

${ }^{53}$ MARTín VAlverde, A. (coord.), La legislación social en la historia de España. De la revolución liberal a 1936, Madrid, 1987, pp.148-151.
} 
La mayor dificultad de este catálogo de mecanismos preventivos fue su cumplimiento. Se trataba de un documento meramente técnico, que alertaba de los riesgos y recomendaba especiales medidas a tener en cuenta, pero en ningún momento obligaba a su adopción o mantenimiento. Por ello, tres años después de su elaboración se advertía que una de las prioridades de la nueva Sección de Industria y Comercio creada en el Ministerio de Agricultura, Industria, Comercio y Obras Públicas, debía ser precisamente la regulación de "las condiciones en las que el trabajo debe llevarse á cabo y los procedimientos que deben tenerse presentes para que ese trabajo, además de dar todos los resultados que de él deben esperarse, se verifique rodeando al obrero de todas las precauciones, de todos los cuidados, que puedan asegurar su integridad física de su organismo y la normalidad de sus funciones" ${ }^{\text {54 }}$. A tal fin, por Real Orden de 29 de enero de 1903 se aprobó la realización de una encuesta a todos los talleres y fábricas del país, por medio de los alcaldes de todos los pueblos, que contenía dos bloques de preguntas sobre "higiene y salubridad general de los talleres" y "precauciones en fabricación".

Sin resultados más precisos, la normativa sobre higiene y seguridad siguió completándose durante esta primigenia fase de desarrollo del derecho obrero español con el concurso de otras leyes específicas o particulares se determinados sectores de la industria, como el nuevo Reglamento de policía minera de 28 de marzo de 1910, el Real Decreto de 18 de octubre de 1913 sobre inspección de sanidad en el campo, o el Real Decreto de 23 enero 1916 sobre condiciones de seguridad en los andamios ${ }^{55}$.

\section{Conclusiones}

Podemos concluir, en suma, que la primera legislación industrial u obrera de higiene y prevención de la seguridad, todavía de un marcado carácter nacional y sin el elemento unificador que más adelante resultarían las recomendaciones de la Organización Internacional del Trabajo (fundada en 1919), se erigió en parte sobre un espíritu de humanidad $\mathrm{y}$, en parte, sobre el mantenimiento de los niveles de competencia económica en el libre mercado, convenciendo a los propios empresarios de su utilidad u provecho también para la productividad, pero sobre una enorme imprecisión doctrinal o científica.

Aunque es cierto que compartió preocupaciones o temas muy similares a los que enfrentó originariamente el modelo británico, apegados a la práctica, podría decirse que en cada país siguió sus propios ritmos y resultó una legislación muy sesgada o parcial,

\footnotetext{
${ }^{54}$ Martín VAlverde, A. (coord.), La legislación social en la historia de España. De la revolución liberal a 1936, Madrid, 1987, p.151.

${ }^{55}$ Martín Valverde, A. (coord.), La legislación social en la historia de España. De la revolución liberal a 1936, Madrid, 1987, pp.154-164.
} 
relacionada con industrias concretas o cuestiones específicas (como los polvos o materiales nocivos, los vapores o la electricidad...), y carente de una buena técnica legislativa, lo que dio como resultado una derecho bastante caótico o desordenado.

También debe señalarse la dependencia directa de la misma con respecto a distintos órganos de la Administración, que la desarrollaban y ejecutaban, o de los servicios de inspección que debían velar por su cumplimiento, en muchas ocasiones con escasos medios e importantes trabas (como la antes citada "mise en demeure" francesa).

No obstante, su principal mérito fue abrir el debate, no sólo sobre la prevención, a través de las concretas medidas de higiene y seguridad, sino también sobre la responsabilidad del empresario o propietario en el caso de los accidentes de trabajo y enfermedades profesionales, señalando un camino que no tardaría en recorrerse a lo largo del siglo $\mathrm{XX}$. 